\title{
Antioxidant and cardioprotective effects of Garcinia indica (kokoberry), an Indian super fruit in isoproterenol induced myocardial necrosis in rats
}

\author{
Vandana Panda ${ }^{\mathrm{a}, *}$, Sonal Kamble ${ }^{\mathrm{a}}$, Yuti Desai ${ }^{\mathrm{a}}$ and S. Sudhamani ${ }^{\mathrm{b}}$ \\ ${ }^{a}$ Department of Pharmacology \& Toxicology, K.M. Kundnani College of Pharmacy, Mumbai, India \\ ${ }^{\mathrm{b}}$ Department of Pathology, D.Y. Patil Medical College, Navi Mumbai, India
}

Received 2 June 2014; accepted 4 July 2014

\begin{abstract}
.
BACKGROUND: Garcinia indica Choisy, a slender evergreen tree is endemic to the west coast of India. The dried rind of the fruit of Garcinia indica is an Indian spice and a food additive. Many therapeutic effects of the fruit have been reported in literature. OBJECTIVE: The present study investigates the cardioprotective and antioxidant activity of a hydroalcoholic extract of Garcinia indica fruit rind (GIE) in isoproterenol (ISO) induced myocardial necrosis in rats.

METHODS: Male Wistar rats were treated with GIE $(400 \& 800 \mathrm{mg} / \mathrm{kg}$, po) daily for 30 days and administered ISO $(85 \mathrm{mg} / \mathrm{kg}$, sc) on the last 2 days at an interval of $24 \mathrm{hr}$ to induce myocardial injury. Activities of marker enzymes (AST, LDH and CK-MB) were assessed in serum and heart. The lipid peroxidation marker malondialdehyde and endogenous antioxidants viz., reduced glutathione, superoxide dismutase, catalase, glutathione peroxidase and glutathione reductase were assayed in heart.

RESULTS: Significant myocardial necrosis, depletion of GSH levels, decrease in antioxidant and marker enzyme activities in the heart homogenate, elevation in malondialdehyde levels and an increase in serum levels of marker enzymes (AST, LDH \& CK-MB) was observed in ISO treated rats when compared with normal rats. Pre-treatment of GIE to ISO treated rats resulted in a significant attenuation of the ISO-elevated levels of serum marker enzymes and malondialdehyde, and restoration of the levels of the ISO-depleted marker enzymes, reduced glutathione and antioxidant enzymes. The biochemical results were corroborated by electrocardiographic and histopathological findings.

CONCLUSION: It may be concluded that GIE oral treatment to ISO challenged rats augments endogenous antioxidants of rat heart, enhances scavenging of free radicals and inhibits lipid peroxidation of membrane, thereby salvaging the myocardium from the deleterious effects of ISO.
\end{abstract}

Keywords: Garcinia indica fruit, isoproterenol, myocaardial necrosis, cardioprotective, antioxidant activity

\section{Introduction}

Cardiovascular Diseases (CVD) remain the principal cause of death in both developed \& developing countries despite several advancements in medical interventions. Among CVD, myocardial infarction accounts for majority of deaths and disabilities [1]. Myocardial Infarction (MI) is the acute condition of necrosis of the myocardium that occurs as a result of imbalance between coronary blood supply \& myocardial demand [2]. Oxidative stress produced by free radicals or reactive oxygen species (ROS), as evidenced by a marked increase in production of

*Corresponding author: Dr. (Mrs.) Vandana Panda, Prin. K.M. Kundnani College of Pharmacy, Jote Joy Building, Rambhau Salgaonkar Marg, Cuffe Parade, Colaba, Mumbai 400005, India. Tel.: +91 22 22164387; Fax: +91 22 22165282; E-mail: vspanda@ rediffmail.com. 
lipid peroxidative products and a transient inhibition of the endogenous antioxidants such as superoxide dismutase, catalase and reduced glutathione has been shown to underlie myocardial damage during myocardial infarction [3]. ISO, a synthetic catecholamine and $\beta$ adrenergic agonist is documented to produce MI in large dose due to generation of highly cytotoxic free radicals through its auto-oxidation [4]. These free radicals stimulate lipid peroxidation \& cause irreversible damage to the myocardial membrane.

India is well known for its rich traditional systems of medicine such as Ayurveda, Siddha and Unani. Recently, there has been a growing interest in establishing the therapeutic potentials of medicinal plants against various diseases such as ischemia, cancer, atherosclerosis, diabetes and liver dysfunction. Notable examples are of Emblica officinalis, Ginkgo biloba, Ocimum sanctum, Terminalia arjuna, Vitis vinifera and Withania somnifera [5]. The Garcinia indica tree is well spread in evergreen tropical rain forests of India and southeast Asia. The dried outer rind of the fruit of Garcinia indica is used for imparting flavor and taste to curries. Many therapeutic effects of the fruit (kokoberry) have been described in Ayurveda, which include its usefulness as an infusion, in skin ailments such as rashes caused by allergies; in treatment of burns, scalds and chaffed skin; as a remedy for dysentery and mucous diarrhoea; as an appetizer and a good liver tonic; as a cardiotonic and for bleeding, piles, dysentery, tumors and heart diseases [6].

The major phyto-constituents of kokoberry are anthocyanins, hydroxycitric acid (HCA), garcinol, isogarcinol and polyphenols. One phyto-constituent, hydroxycitric acid (HCA), has been patented for use as a hypocholesterolaemic agent [7]. Garcinol, a polyisoprenylated benzophenone purified from the kokoberry rind displays anti-cancer and antioxidant activities [(8]. Apart from HCA and garcinol, kokoberry contains other compounds like isogarcinol, ascorbic acid and polyphenols with potential antioxidant properties.

Keeping in view the use of the Garcinia indica fruit in treatment of heart ailments in traditional medicine and the potent lipid lowering and antioxidant effects of its constituents, the present study was undertaken to evaluate the cardioprotective activity of $G$. indica fruit rind against ISO induced myocardial necrosis in rats.

\section{Materials and methods}

\subsection{Drugs and chemicals}

Thiobarbituric acid (TBA), trichloroacetic acid (TCA), reduced glutathione, oxidized glutathione and nicotinamide adenine dinucleotide phosphate (NADPH) were obtained from Himedia Laboratories, Mumbai, India. Gemfibrozil, isoproterenol (ISO), epinephrine, and 5, 5' - dithiobis(2-nitrobenzoic acid) - (DTNB) were purchased from Sigma Chemical Co., St Louis, MO, USA. All other chemicals were obtained from local sources and were of analytical grade.

\subsection{Preparation of plant extract}

The fruits of $G$. indica were collected from the Konkan region of Maharashtra, India, air dried under shade, powdered mechanically and stored in air tight containers. The powder was extracted using a mixture of methanol: water $(70: 30)$ in a soxlet apparatus. This extract (GIE) was dried and stored in a refrigerator for further use. The plant was authenticated at the Blatter Herbarium, St. Xavier's College, Mumbai after matching with the existing specimen (accession no. 03587).

\subsection{Isolation and characterization}

\subsubsection{Isolation of active constituent by HPTLC}

An active phyto-constituent was isolated from GIE by HPTLC. Precoated silica gel 60 F254 (Merck) plates were used as stationary phase. The mobile phase comprised toluene: ethyl acetate: formic Acid $(8: 2: 1)$. The constituent at RF 0.46 was marked, scraped out from the plate and eluted from the stationary phase using methanol. Silica gel was removed from the solution by centrifugation at $3000 \mathrm{rpm}$ and the supernatant was evaporated at a temperature not exceeding $50^{\circ} \mathrm{C}$ to get the active phyto-constituent. 


\subsection{Characterization of isolated phyto-constituent}

The isolated phyto-constituent was characterized using UV spectroscopy, IR spectroscopy, HPLC and Mass Spectroscopy.

\subsubsection{UV Spectrum}

The isolated constituent was dissolved in methanol and scanned in the UV range from 200-600 nm in a Jasco UV $-550 \mathrm{UV} / \mathrm{Vis}$ Spectrophotometer. The wavelength of maximum absorption was observed from the UV spectrum.

\subsubsection{IR Spectrum}

The isolated constituent was mixed with KBR in the proportion of $1: 100$ and the IR spectrum was recorded in a Shimadzu IR Affinity Spectrophotometer.

\subsubsection{HPLC}

The isolated constituent was subjected to HPLC analysis using isocratic Jasco HPLC system with the following specifications: Column: Qualisil BDS C18 Column; Flow Rate: $1 \mathrm{ml} / \mathrm{min}$; Mobile Phase: Methanol; Detector: UV detector $(280 \mathrm{~nm})$.

\subsubsection{Mass spectrum}

The mass spectrum of the purified isolated constituent was recorded using ABSCIX (API 3200) spectrometer.

\subsection{Evaluation of cardioprotective activity}

\subsubsection{Experimental animals}

Male Wistar albino rats of 150-200 g were housed in clean polypropylene cages under standard conditions of humidity $(50 \pm 5 \%)$, temperature $\left(25 \pm 2^{\circ} \mathrm{C}\right)$ and light $(12 \mathrm{~h}$ light $/ 12 \mathrm{~h}$ dark cycle $)$ and fed with a standard diet (Amrut laboratory animal feed, Nava Maharashtra Chakan Oil Mills, Pune, India) and water ad libitum. All animals were handled with humane care. Experimental protocols were reviewed and approved by the Institutional Animal Ethics Committee (Animal House Registration No. 25/1999/CPCSEA) and conform to the Indian National Science Academy Guidelines for the Use and Care of Experimental Animals in Research.

\subsection{Preparation of GIE and ISO solutions}

- The dried hydroalcoholic extract of Garcinia indica fruit rind (GIE) was dissolved in distilled water and used.

- Gemfibrozil was dissolved in distilled water and used immediately for oral administration.

- Isoproterenol (ISO) was dissolved in distilled water and used immediately for subcutaneous administration.

\subsection{Experimental procedure}

Wistar rats were randomly divided into five groups with six rats in each group and treated in the following way: Group I (Normal control): Rats were administered distilled water ( $1 \mathrm{ml} / \mathrm{kg}$, p.o.) once daily for 30 days.

Group II (Toxicant Control): Rats were administered distilled water ( $1 \mathrm{ml} / \mathrm{kg}$, p.o.) daily for 30 days and in addition received ISO $(85 \mathrm{mg} / \mathrm{kg}$, s.c.) on the 29th and 30th day at an interval of $24 \mathrm{~h}$.

Group III (GIE 400 group): Rats were administered GIE ( $400 \mathrm{mg} / \mathrm{kg}$, p.o.) daily for 30 days and in addition received ISO $(85 \mathrm{mg} / \mathrm{kg}$, s.c. $)$ on the 29 th and 30 th day at an interval of $24 \mathrm{~h}$.

Group IV (GIE 800 group): Rats were administered GIE ( $800 \mathrm{mg} / \mathrm{kg}$, p.o.) daily for 30 days and in addition received ISO $(85 \mathrm{mg} / \mathrm{kg}$, s.c. $)$ on the 29 th and 30th days at an interval of $24 \mathrm{~h}$.

Group V (Standard group): Rats were administered Gemfibrozil (50 mg/kg, p.o.) daily for 30 days and in addition received ISO $(85 \mathrm{mg} / \mathrm{kg}$, s.c.) on the 29 th and 30th day at an interval of $24 \mathrm{~h}$.

Electrocardiograms were recorded on the $31 \mathrm{st}$ day, $24 \mathrm{~h}$ after the last subcutaneous injection. All the rats were sacrificed by cervical dislocation. Blood was collected by cardiac puncture and allowed to clot for $30 \mathrm{~min}$ at room 
temperature. The serum was separated by centrifugation at $2500 \mathrm{rpm}$ at $30^{\circ} \mathrm{C}$ for $15 \mathrm{~min}$ and used for the estimation of the marker enzymes AST, LDH and CK-MB. The hearts were dissected immediately, washed with ice-cold saline and divided into 2 equal parts. One part was used to prepare $10 \%(\mathrm{w} / \mathrm{v})$ homogenate in phosphate buffer $(50 \mathrm{mM}, \mathrm{pH}$ 7.4). An aliquot was used for the determination of lipid peroxidation (LPO). The homogenates were centrifuged at $7000 \times \mathrm{g}$ for $10 \mathrm{~min}$ at $4^{\circ} \mathrm{C}$ and the supernatants were used for the assays of AST, LDH, CK-MB, reduced glutathione (GSH), superoxide dismutase (SOD), catalase (CAT), glutathione peroxidase (GPx) and glutathione reductase (GR). The remaining part of the heart was fixed in $10 \%$ buffered formalin and used for histological studies.

\subsection{Marker enzyme assays}

The marker enzymes AST, LDH \& CK-MB were assayed in serum and heart using standard kits supplied from Accurex Biochemicals, Mumbai, India and Erba Mannheim, Germany. The results were expressed as IU/L for AST, $\mathrm{LDH} \& \mathrm{CK}-\mathrm{MB}$.

\subsection{Protein estimation}

The levels of total proteins were determined in heart homogenates of experimental animals by the method of Lowry et al using bovine serum albumin as standard [9].

\subsection{Lipid peroxidation}

The quantitative estimation of LPO was done by determining the concentration of Thiobarbituric Acid Reactive Substances (TBARS) in heart using the method of Ohkawa, Ohishi, and Yagi [10]. The amount of malondialdehyde (MDA) formed was quantified by reaction with TBA and used as an index of lipid peroxidation. The results were expressed as nmol of MDA/g of wet tissue using molar extinction coefficient of the chromophore $\left(1.56 \times 10^{-5} / \mathrm{M} / \mathrm{cm}\right)$ and 1,1,3,3-tetraethoxypropane as standard.

\subsection{Glutathione estimation}

GSH was estimated in the heart homogenate using DTNB by the method of Ellman [11]. The absorbance was read at $412 \mathrm{~nm}$ and the results were expressed as $\mu \mathrm{mol}$ of GSH/g of wet tissue.

\subsection{Antioxidant enzyme assays in heart homogenate}

Superoxide dismutase (SOD) was assayed by the method of Sun \& Zigman in which the activity of SOD was inversely proportional to the concentration of its oxidation product adrenochrome, which was measured spectrophotometrically at $320 \mathrm{~nm}$ [12]. 1 unit of SOD activity is defined as enzyme concentration required to inhibit the rate of auto-oxidation of epinephrine by $50 \%$ in $1 \mathrm{~min}$ at $\mathrm{pH} 10$.

Catalase (CAT) was estimated by the method of Clairborne, which is a quantitative spectroscopic method developed for following the breakdown of $\mathrm{H}_{2} \mathrm{O}_{2}$ at $240 \mathrm{~nm}$ in unit time for routine studies of catalase kinetics [13].

Glutathione peroxidase (GPx) estimation was carried out using the method of Rotruck et al., which makes use of the following reaction [14].

$$
\mathrm{H}_{2} \mathrm{O}_{2}+2 \mathrm{GSH} \rightarrow 2 \mathrm{H}_{2} \mathrm{O}+\mathrm{GSSG} \text { (oxidized glutathione). }
$$

GPx in the tissue homogenate oxidizes glutathione and simultaneously, $\mathrm{H}_{2} \mathrm{O}_{2}$ is reduced to water. This reaction is arrested at 10 min using trichloroacetic acid and the remaining glutathione is reacted with DTNB solution to result in a colored compound, which is measured spectrophotometrically at $420 \mathrm{~nm}$.

Glutathione reductase (GR) activity was determined by using the method of Mohandas et al., in which the following reaction is implicated [15].

$$
\mathrm{NADPH}+\mathrm{H}^{+}+\mathrm{GSSG} \rightarrow \mathrm{NADP}^{+}+2 \mathrm{GSH}
$$


In presence of GR, oxidized glutathione undergoes reduction and simultaneously, NADPH is oxidized to NADP ${ }^{+}$. Enzyme activity is quantified at room temperature by measuring spectrophotometrically at $340 \mathrm{~nm}$, the disappearance of NADPH/min.

\subsection{Histopathological studies}

The parts of the hearts which were stored in $10 \%$ buffered formalin were embedded in paraffin, sections cut at $5 \mu \mathrm{m}$ and stained with hematoxylin and eosin. These sections were then examined under a light microscope for histo-architectural changes.

\subsection{Statistical analysis}

The results of cardioprotective activity are expressed as mean \pm SEM from 6 animals in each group. Results were statistically analyzed using one-way ANOVA followed by Bonferroni's Multiple Comparison test; $P<0.05$ was considered significant. GraphPad Version 5.00 of Graph Pad Software Inc., San Diego, USA was the software used for statistical analysis.

\section{Results}

\subsection{Isolation and characterization}

\subsubsection{UV spectrum (Fig. 1)}

The wavelength of maximum absorption $(\lambda \max )$ of the isolated constituent was observed to be at $280 \mathrm{~nm}$ which matches with that of garcinol from literature [8].

\subsubsection{IR spectrum (Fig. 2)}

The IR spectrum of the isolated constituent showed the following peaks with the following assignments:

\begin{tabular}{lcc}
\hline Frequency $\left(\mathrm{cm}^{-1}\right)$ & Bond & Possible group assignment \\
\hline $3500-3200$ & $-\mathrm{O}-\mathrm{H}$ stretching & Hydroxyl \\
$3300-3270$ & $-\mathrm{C}-\mathrm{H}$ stretching & Aromatics \\
$3000-2850$ & $-\mathrm{C}-\mathrm{H}$ stretching & Alkanes \\
$1653-1635$ & $-\mathrm{C}=\mathrm{O}$ & $\alpha-\beta$ Unsaturated Carboxylic group \\
$1500-1400$ & $-\mathrm{C}-\mathrm{H}$ stretching & Aromatics \\
$1320-1000$ & $-\mathrm{C}-\mathrm{O}$ stretching & Carboxylic acid \\
\hline
\end{tabular}

The above spectral findings matched with those of garcinol reported in literature [8].

\subsubsection{HPLC (Fig. 3)}

The HPLC chromatogram of the isolated phyto-constituent exhibited a retention time of $7.10 \mathrm{~min}$ at $280 \mathrm{~nm}$ which matches with that of garcinol reported in previous documented studies [16, 17].

\subsubsection{Mass spectrum (Fig. 4)}

The mass spectrum of the isolated constituent showed molecular ion peak at $\mathrm{m} / \mathrm{z} 603.3$ which matches with that of garcinol which is reported to be 602 in literature $[16,17]$. 


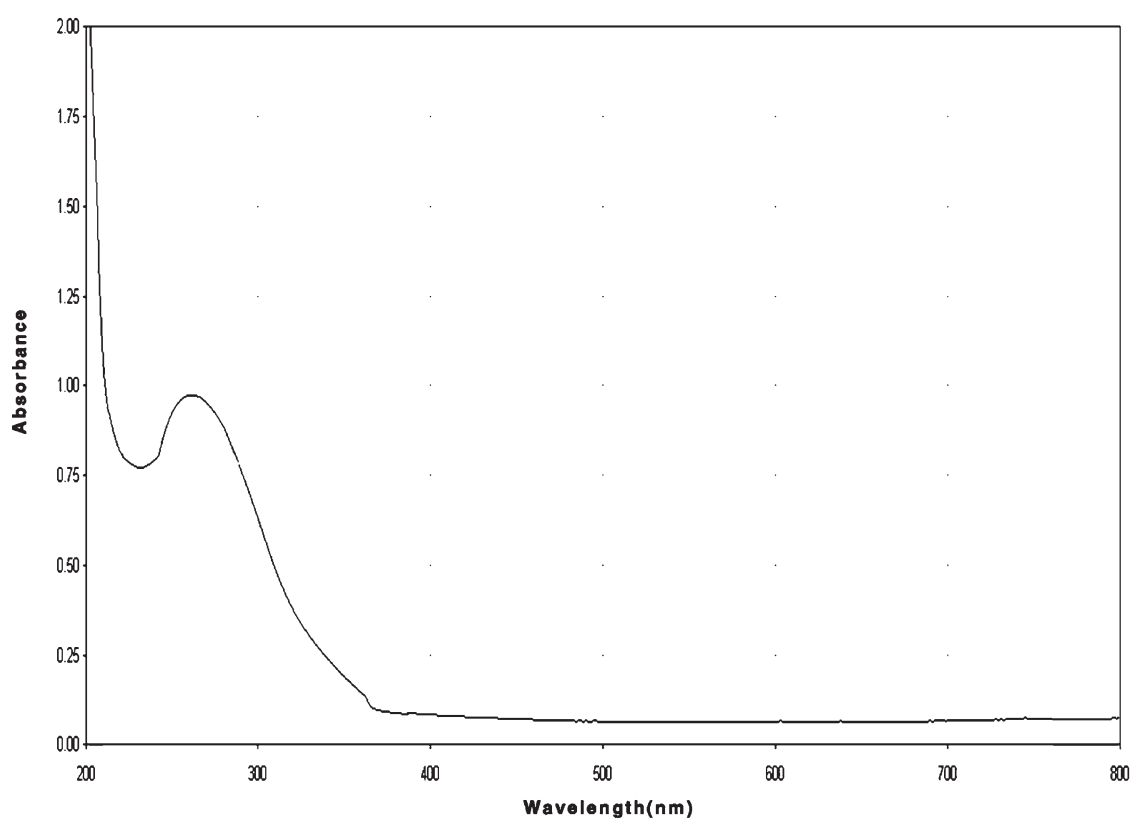

\begin{tabular}{|c|c|}
\hline$\Lambda \max$ & Absorbance \\
\hline $280 \mathrm{~nm}$ & 0.9871 \\
\hline
\end{tabular}

Fig. 1. UV spectrum of garcinol.

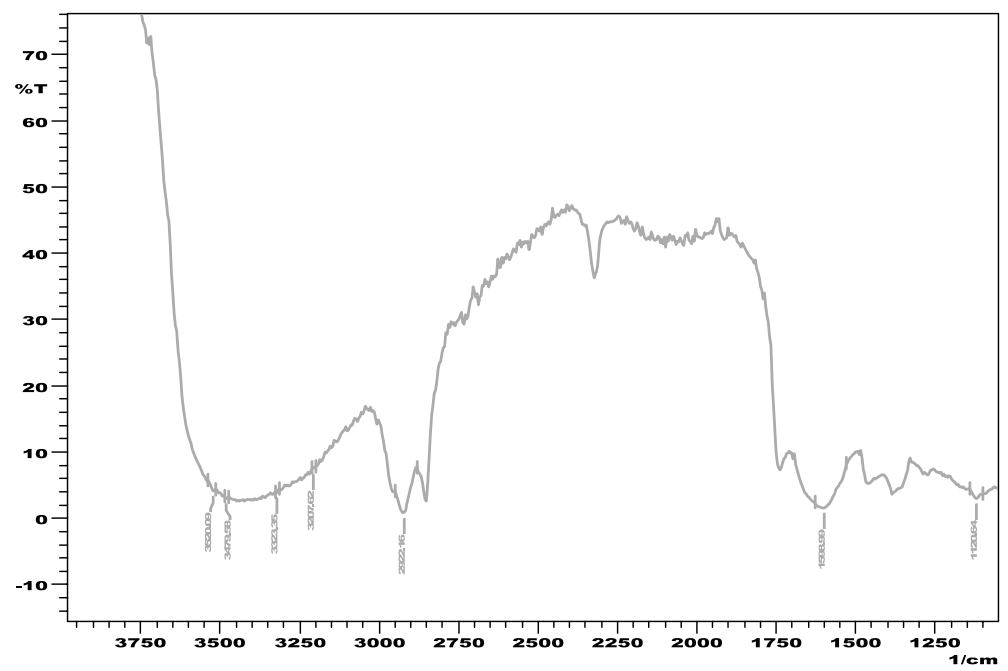

Fig. 2. IR spectrum of garcinol. 


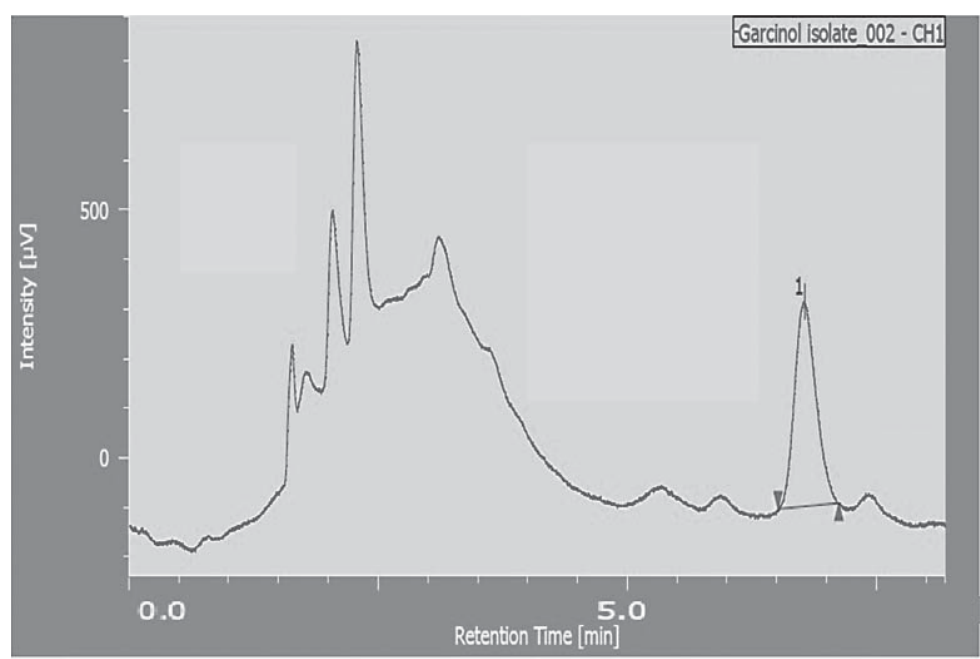

\begin{tabular}{|l|l|l|l|l|l|}
\hline No & Peak name & tR(min) & Area & NTP & Symmetry \\
\hline 1 & Garcinol & 7.106 & 12244 & 4745 & 1.183 \\
\hline
\end{tabular}

Fig. 3. HPLC chromatogram of garcinol at $280 \mathrm{~nm}$.

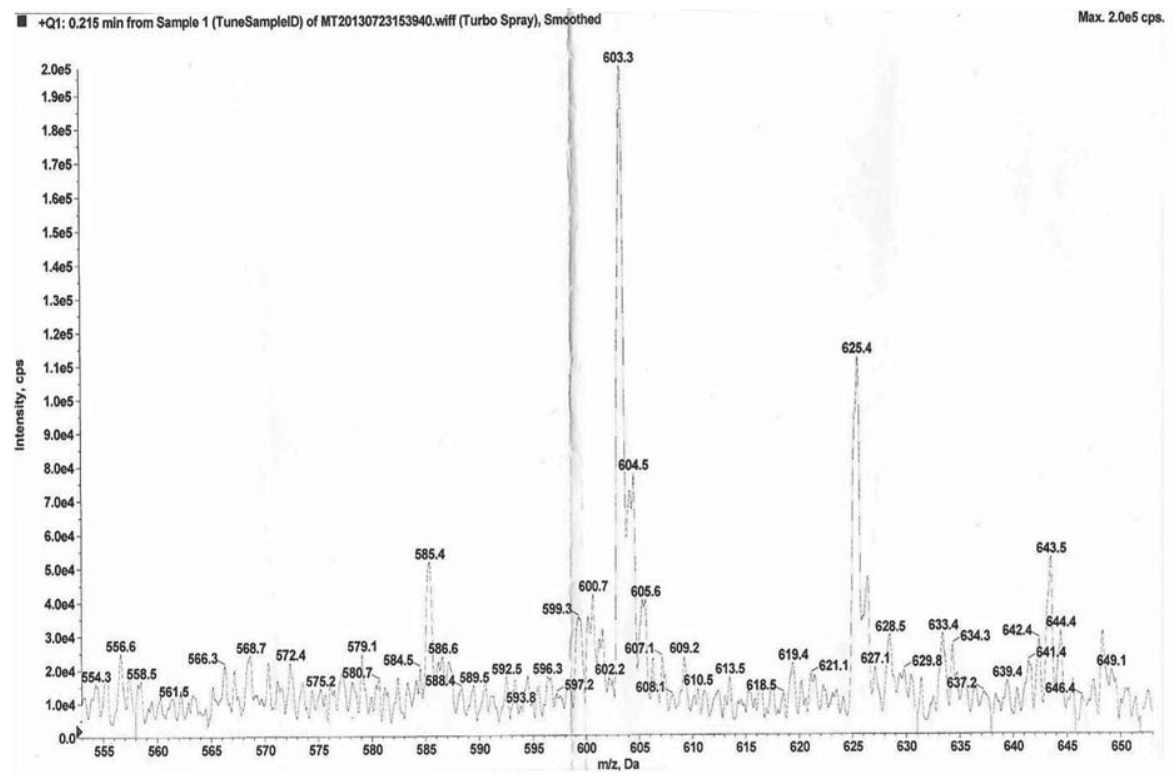

Fig. 4. Mass Spectrum of garcinol.

\subsection{Electrocardiographic studies}

ECG recordings were made on bi-polar standard leads viz., Lead-I, Lead-II and Lead-III. In all cases of myocardial infarction, Lead II showed clear and distinct individual waves when compared with Lead I and Lead III. Therefore, ECG was monitored on Lead II only. Normal control animals showed a normal ECG pattern (Fig. 5.1) whereas 


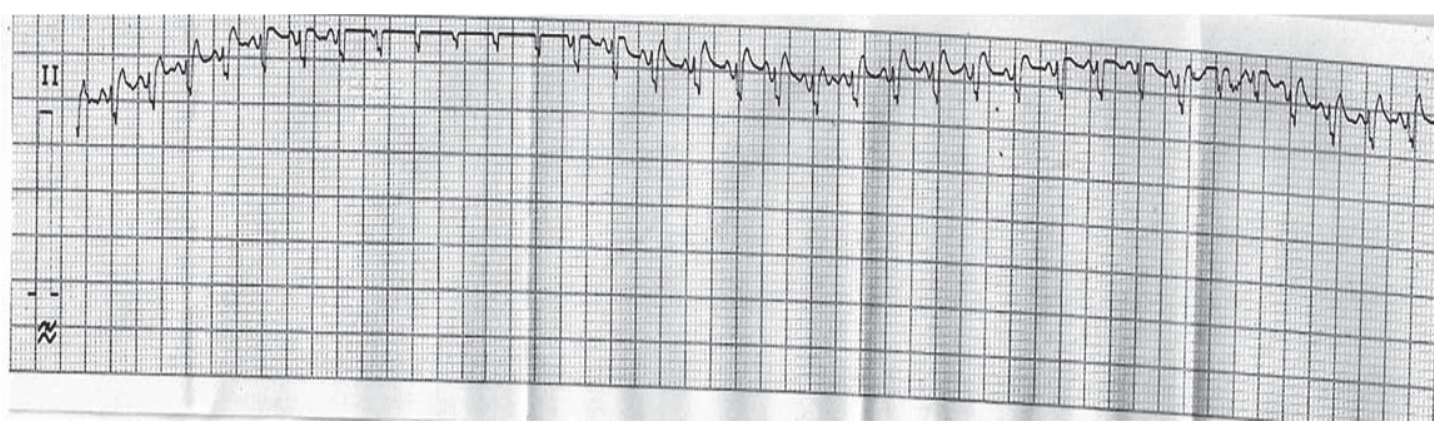

Fig. 5.1. ECG of heart of normal rat.

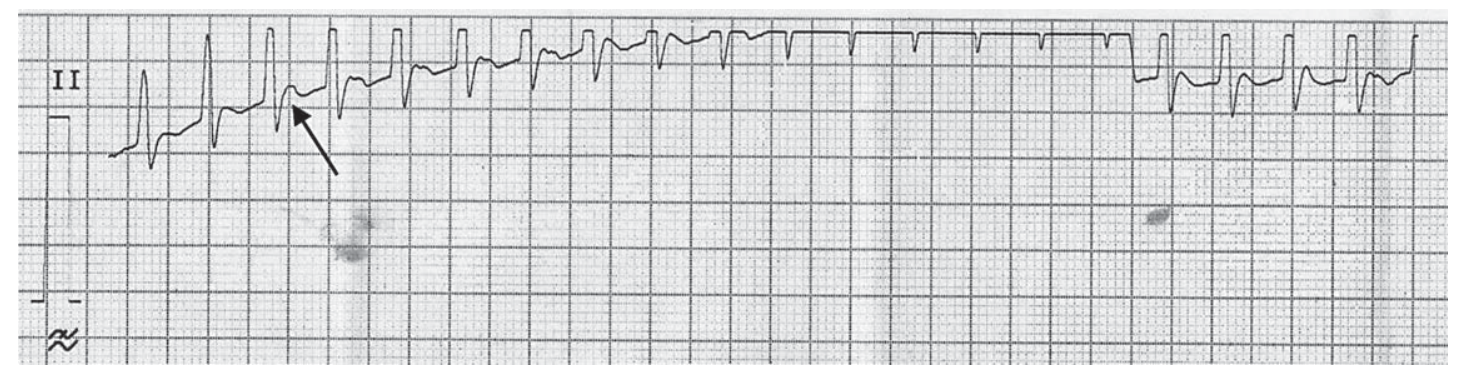

Fig. 5.2. ECG of heart of ISO $(85 \mathrm{mg} / \mathrm{kg})$ treated rat. Prominent ST segment elevation is noted.

Table 1

Effect of GIE treatment on electrocardiographic changes

\begin{tabular}{|c|c|c|c|c|c|}
\hline Groups & Normal & ISO (Toxicant) & Gemfibrozil (Std) & GIE 400 & GIE 800 \\
\hline Heart Rate (BPM) & $288.00 \pm 14.43$ & $575.00 \pm 17.08^{\mathrm{a}}$ & $350.00 \pm 12.91^{* *}$ & $482.00 \pm 7.35^{* *}$ & $409.00 \pm 7.35^{* *}$ \\
\hline $\mathrm{P}$ wave width (s) & $0.05 \pm 0.02$ & $0.02 \pm 0.02^{\mathrm{a}}$ & $0.04 \pm 0.02^{* *}$ & $0.02 \pm 0.02^{*}$ & $0.03 \pm 0.02^{* *}$ \\
\hline $\mathrm{P}$ wave height $(\mathrm{mV})$ & $0.22 \pm 0.01$ & $0.63 \pm 0.03^{\mathrm{a}}$ & $0.33 \pm 0.03^{* *}$ & $0.53 \pm 0.02^{*}$ & $0.43 \pm 0.01^{* *}$ \\
\hline QRS wave width (s) & $0.05 \pm 0.01$ & $0.02 \pm 0.01^{\mathrm{a}}$ & $0.04 \pm 0.01^{* *}$ & $0.03 \pm 0.01^{*}$ & $0.03 \pm 0.01^{* *}$ \\
\hline QRS wave height (mV) & $0.09 \pm 0.01$ & $0.56 \pm 0.03^{\mathrm{a}}$ & $0.23 \pm 0.02^{* *}$ & $0.43 \pm 0.02^{* *}$ & $0.31 \pm 0.01^{* *}$ \\
\hline PR interval (s) & $0.022 \pm 0.001$ & $0.067 \pm 0.002^{\mathrm{a}}$ & $0.033 \pm 0.003^{* *}$ & $0.054 \pm 0.005^{*}$ & $0.048 \pm 0.0014^{* *}$ \\
\hline QT interval (s) & $0.085 \pm 0.006$ & $0.383 \pm 0.011^{\mathrm{a}}$ & $0.148 \pm 0.004^{* *}$ & $0.265 \pm 0.015^{*}$ & $0.198 \pm 0.005^{* *}$ \\
\hline ST segment & $0.06047 \pm 0.00082$ & $0.16180 \pm 0.01967^{\mathrm{a}}$ & $0.07747 \pm 0.01346^{* *}$ & $0.09883 \pm 0.00638^{*}$ & $0.07768 \pm 0.01346^{* *}$ \\
\hline
\end{tabular}

All values are expressed as Mean $\pm \operatorname{SEM}, N=6$ in each group. ${ }^{a} p<0.001$ when Toxicant group is compared with Normal group. ${ }^{* *} p<0.001$, ${ }^{*} p<0.01$ when treatment groups compared with toxicant group.

animals treated with ISO alone showed a significant $(p<0.001)$ reduction in $\mathrm{P}$ wave and QRS complex widths, and a significant increase $(p<0.001)$ in $\mathrm{P}$ wave and QRS complex heights when compared with normal animals (Fig. 5.2). In addition, there was a significant increase $(p<0.001)$ in heart rate, prolongation of QT and PR intervals and a significant elevation $(p<0.001)$ in ST segment in ISO treated animals when compared with normal animals (Table 1).

GIE treatment significantly $(p<0.001)$ reduced the ISO elevated heart rate and produced a significant increase in $\mathrm{P}$ wave and QRS wave width decreased by ISO (Figs. 5.3 and 5.4 for GIE $400 \mathrm{mg} / \mathrm{kg}$ and GIE $800 \mathrm{mg} / \mathrm{kg}$ respectively). It also decreased significantly the ISO-elevated $\mathrm{P}$ wave and QRS wave height and prevented any significant prolongation of QT and PR intervals and elevation in ST segment. The ECG of GIE $800 \mathrm{mg} / \mathrm{kg}$ was comparable to that of the standard drug gemfibrozil $(50 \mathrm{mg} / \mathrm{kg})$ which showed a pattern almost comparable to the normal ECG (Fig. 5.5). 


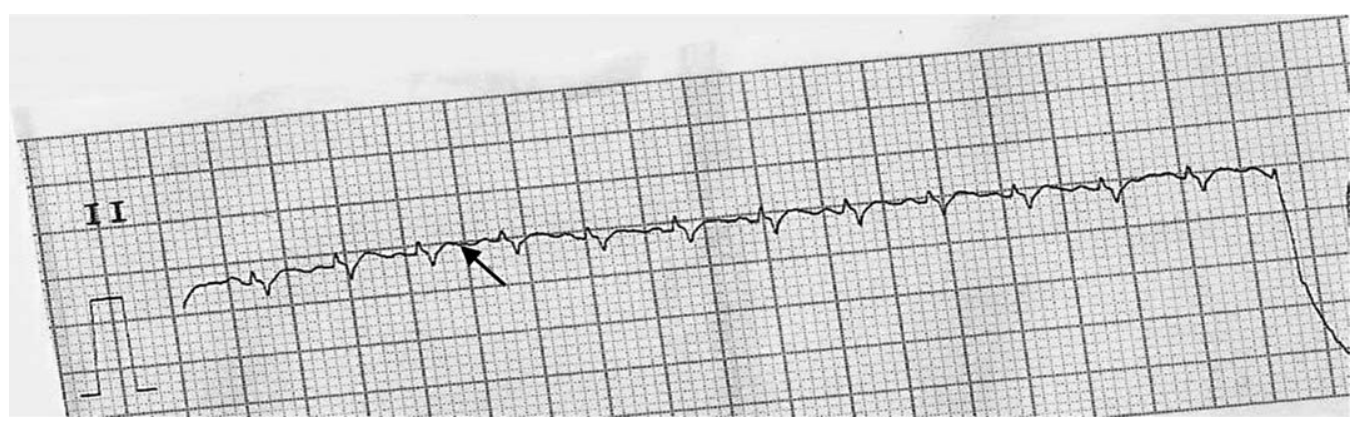

Fig. 5.3. ECG of heart of GIE $400 \mathrm{mg} / \mathrm{kg}$ treated rat. No ST segment elevation is observed.

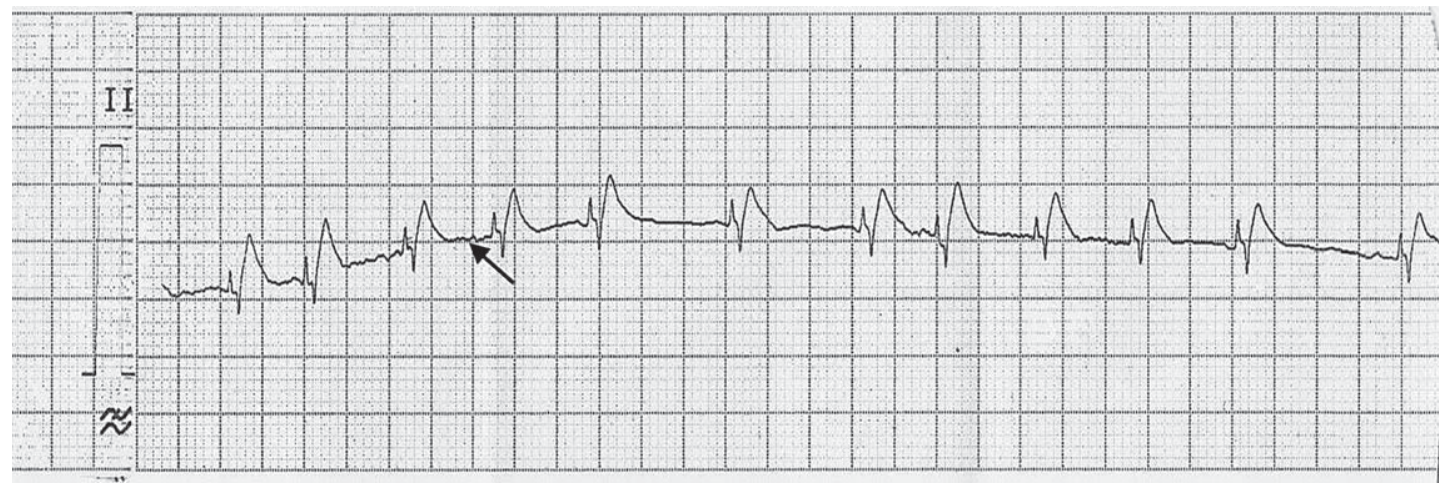

Fig. 5.4. ECG of heart of GIE $800 \mathrm{mg} / \mathrm{kg}$ treated rat. No ST segment elevation is seen.

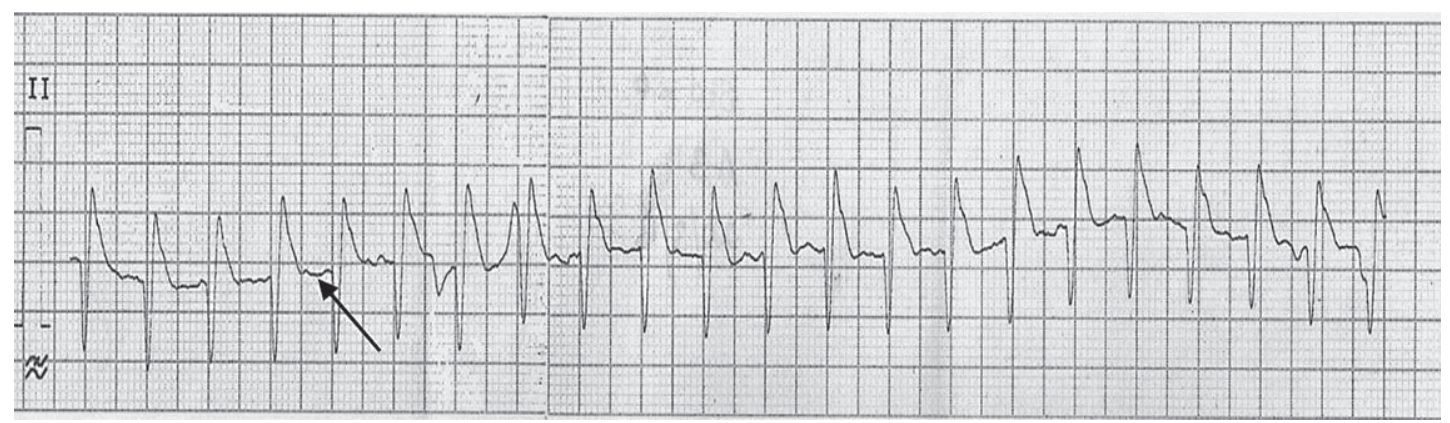

Fig. 5.5. ECG of heart of gemfibrozil $(50 \mathrm{mg} / \mathrm{kg})$ treated rat. No ST segment elevation is observed and the ECG is similar to normal.

\subsection{Biochemical parameters}

\subsubsection{Serum marker enzymes}

The effect of GIE on serum marker enzymes AST, LDH and CK-MB is shown in Fig. 6. Rats treated with ISO showed a significant increase in the serum activities of the marker enzymes when compared with the normal group of rats. Pre-treatment of GIE $400 \mathrm{mg} / \mathrm{kg}$, GIE $800 \mathrm{mg} / \mathrm{kg}$ and gemfibrozil for 30 days to ISO intoxicated rats decreased significantly the elevated activities of these enzymes. 


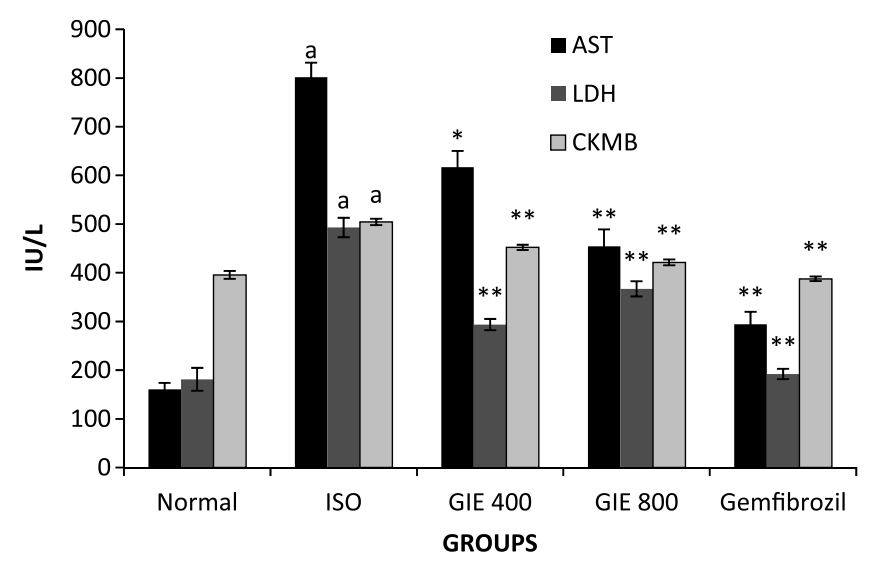

Fig. 6. Effect of GIE on serum marker enzymes (AST, LDH, CK-MB) in ISO intoxicated rats.

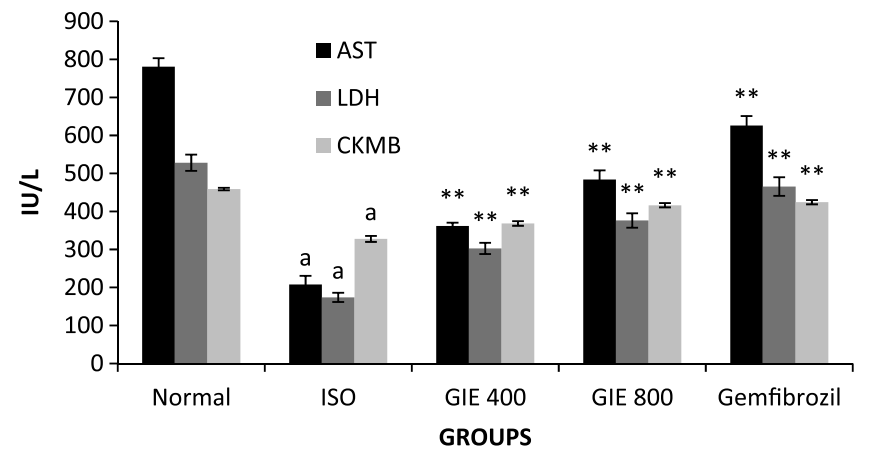

Fig. 7. Effect of GIE on heart marker enzymes (AST, LDH, CK-MB) in ISO intoxicated rats. All values are expressed as Mean \pm SEM, $N=6$ in each group. ${ }^{\mathrm{a}} p<0.001$ when Toxicant group is compared with Normal group. ${ }^{* *} p<0.001,{ }^{*} p<0.01$ when treatment groups compared with toxicant group.

\subsection{Heart marker enzymes}

Marker enzyme activities of AST, LDH and CK-MB were assayed in cardiac tissue. The effect of GIE treatment on marker enzymes in heart is presented in Fig. 7. The ISO control group of rats exhibited significant decrease in AST, LDH and CK-MB activities when compared with the normal rats. Treatment with GIE $400 \mathrm{mg} / \mathrm{kg}, \mathrm{GIE} 800 \mathrm{mg} / \mathrm{kg}$ and gemfibrozil for 30 days to ISO treated rats caused a significant restoration in the activities of AST, LDH and CK-MB depleted by ISO.

\subsection{Antioxidant enzymes, GSH and LPO}

The effect of GIE on antioxidant enzymes, LPO and GSH is summarized in Tables 2 and 3. MDA, the myocardial LPO marker was significantly elevated in the ISO control group of rats when compared with the normal group. Pretreatment of GIE $400 \mathrm{mg} / \mathrm{kg}$, GIE $800 \mathrm{mg} / \mathrm{kg}$ and gemfibrozil for 30 days to ISO treated rats prevented significantly the increased formation of MDA.

Significant depletion in myocardial GSH level was observed in the ISO treated group when compared with the normal group of the rats. Pre-treatment of GIE $400 \mathrm{mg} / \mathrm{kg}$, GIE $800 \mathrm{mg} / \mathrm{kg}$ and gemfibrozil orally for 30 days to ISO treated rats significantly restored the ISO depleted GSH levels. 
Table 2

Effect of GIE on heart SOD, CAT and MDA in ISO intoxicated rats

\begin{tabular}{lccr}
\hline Treatment & SOD U/mg protein & CAT U/mg protein & MDA (nmol/g wet tissue) \\
\hline Normal & $22.04 \pm 0.87$ & $18.40 \pm 0.40$ & $56.83 \pm 2.35$ \\
ISO (Toxicant) & $5.25 \pm 0.41^{\mathrm{a}}$ & $6.63 \pm 0.35^{\mathrm{a}}$ & $180.20 \pm 5.69^{\mathrm{a}}$ \\
Gemfibrozil (Standard) & $19.54 \pm 0.61^{*}$ & $16.92 \pm 0.19^{*}$ & $71.83 \pm 2.73^{*}$ \\
GIE 400 & $10.02 \pm 0.85^{*}$ & $12.08 \pm 0.33^{*}$ & $125.20 \pm 3.70^{*}$ \\
GIE 800 & $13.01 \pm 0.55^{*}$ & $15.12 \pm 0.50^{*}$ & $92.11 \pm 3.50^{*}$ \\
\hline
\end{tabular}

All values are expressed as Mean \pm S.E.M, $N=6$ in each group. ${ }^{a} p<0.001$ when Toxicant group is compared with Normal group. ${ }^{*} p<0.001$ when treatment groups compared with toxicant group. 1 unit of $\mathrm{CAT}=\mu \mathrm{mol} \mathrm{H}_{2} \mathrm{O}_{2}$ consumed/min/mg protein.

Table 3

Effect of GIE on heart GSH, GPx and GR in ISO intoxicated rats

\begin{tabular}{lccr}
\hline Treatment & GSH $\mu$ mol/g wet tissue & GPx U/mg protein & GR U/mg protein \\
\hline Normal & $10.83 \pm 0.22$ & $16.87 \pm 0.99$ & $222.50 \pm 5.84$ \\
ISO (Toxicant) & $3.12 \pm 0.33^{\mathrm{a}}$ & $6.40 \pm 0.46^{\mathrm{a}}$ & $52.28 \pm 4.81^{\mathrm{a}}$ \\
Gemfibrozil (Standard) & $8.87 \pm 0.33^{*}$ & $13.7 \pm 0.39^{*}$ & $206.70 \pm 4.67^{*}$ \\
GIE 400 & $6.56 \pm 0.19^{*}$ & $9.60 \pm 0.34^{*}$ & $115.40 \pm 6.24^{*}$ \\
GIE 800 & $7.80 \pm 0.15^{*}$ & $12.20 \pm 0.47^{*}$ & $151.00 \pm 6.11^{*}$ \\
\hline
\end{tabular}

All values are expressed as Mean \pm S.E.M, $N=6$ in each group. ${ }^{a} p<0.001$ when Toxicant group is compared with Normal group. ${ }^{*} p<0.001$ when treatment groups compared with toxicant group. 1 unit of GPX $=\mu \mathrm{g} \mathrm{GSH}$ utilized $/ \mathrm{min} / \mathrm{mg}$ protein. 1 unit of GR $=\mathrm{nmol} \mathrm{NADPH}$ oxidized/min/mg protein.

ISO treatment induced a significant depletion in activities of the antioxidant enzymes SOD, CAT, GPx and GR in the hearts of normal rats. Pre-treatment of GIE $400 \mathrm{mg} / \mathrm{kg}$, GIE $800 \mathrm{mg} / \mathrm{kg}$ and gemfibrozil for 30 days followed by ISO injection on the 29th and 30th day to rats significantly restored the ISO depleted activities of SOD, CAT, GPX and GR.

\subsection{Histopathology}

Histopathological studies on heart tissues of normal control group of rats revealed a normal histoarchitecture of the heart with intact cardiac muscle fibres and blood vessels without signs of separation, edema or any other abnormality (Fig. 8.1) Heart tissues of rats injected with ISO showed myocardial degeneration, mononuclear infiltration, separation

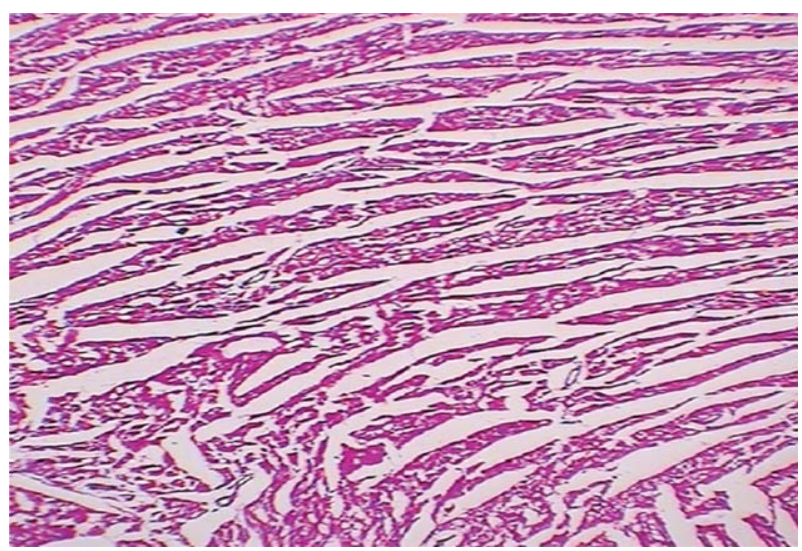

Fig. 8.1. Haematoxylin and eosin staining of heart of normal rat $10 \times 10 x=100 x$. 


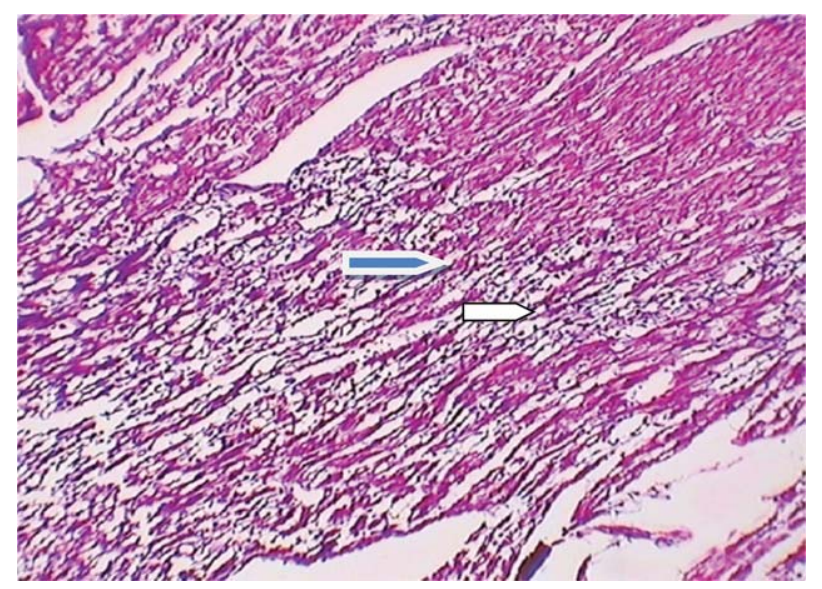

Fig. 8.2. Haematoxylin and eosin staining of heart of ISO $(85 \mathrm{mg} / \mathrm{kg}$, sc) treated rat $10 \times 10 \mathrm{x}=100 \mathrm{x}$. Pointers indicate myocardial degeneration and vacuolation.

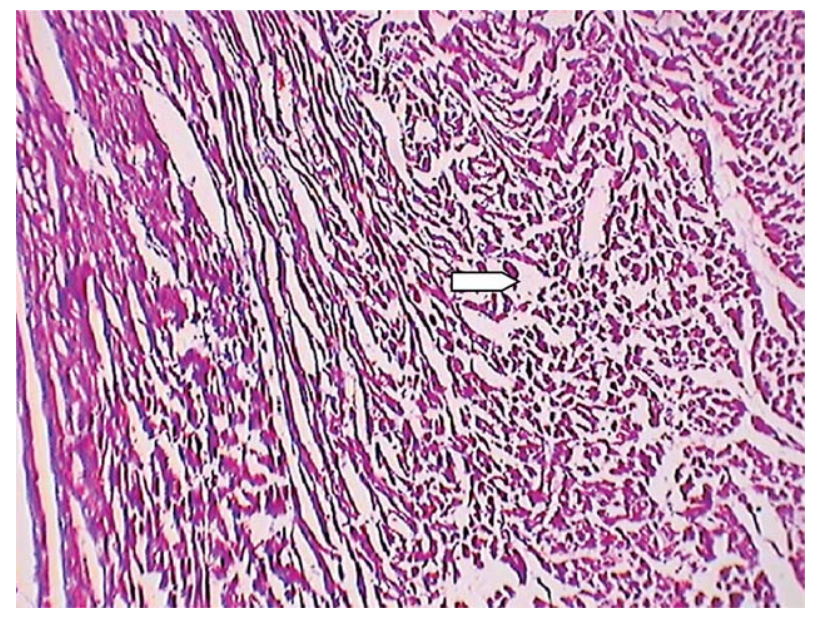

Fig. 8.3. Haematoxylin and eosin staining of heart of rat treated with Gemfibrozil $(500 \mathrm{mg} / \mathrm{kg}$, po) and ISO $(85 \mathrm{mg} / \mathrm{kg}, \mathrm{sc}) 10 \times 10 \mathrm{x}=100 \mathrm{x}$. Pointer indicates amelioration of myocardial degeneration.

of cardiac muscle fibres, vacuolation and dilation of blood vessels (Fig. 8.2). The gemfibrozil treated hearts (Fig. 8.3) showed less severity of lesions, lesser myocardial degeneration and lesser vacuolation in comparison with the hearts of ISO treated rats. Treatment with GIE $(400 \mathrm{mg} / \mathrm{kg}$ and $800 \mathrm{mg} / \mathrm{kg})$ showed a dose dependent decrease in the levels of degeneration, edema, vacuolation and infiltration of inflammatory cells when compared with the ISO group and showed protection which was comparable with standard treatment (Figs. 8.4 and 8.5 respectively).

\section{Discussion}

Isoproterenol, a synthetic $B$ adrenergic agonist by its positive inotropic and chronotropic actions increases the myocardial oxygen demand that leads to ischemic necrosis of myocardium in rats. A number of patho-physiologic mechanisms have been postulated to explain the ISO-induced myocardial damage, viz., altered permeability, increased turnover of norepinephrine and generation of cytotoxic free radicals on auto-oxidation of catecholamine. Free radical 


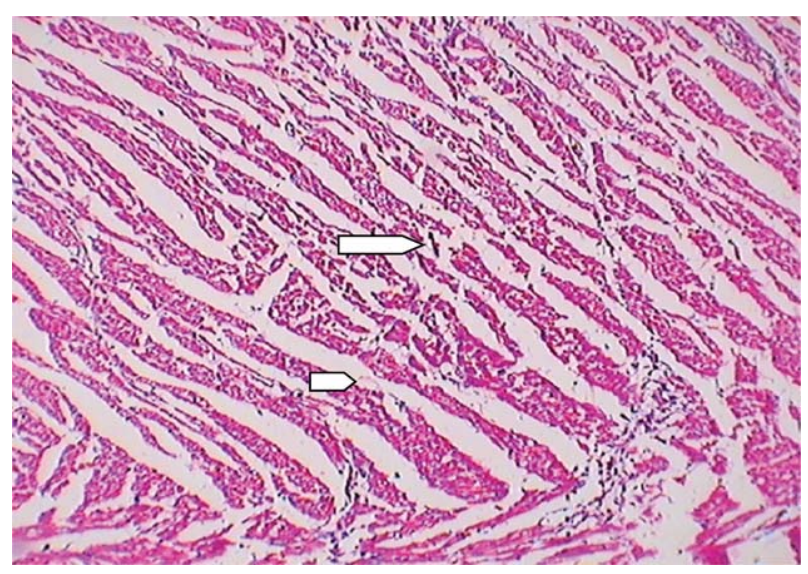

Fig. 8.4. Haematoxylin and eosin staining of heart of rat treated with GIE $(400 \mathrm{mg} / \mathrm{kg}$, po $)$ and ISO $(85 \mathrm{mg} / \mathrm{kg}, \mathrm{sc}) 10 \times 10 \mathrm{x}=100 \mathrm{x}$. Pointers indicate amelioration of myocardial degeneration.

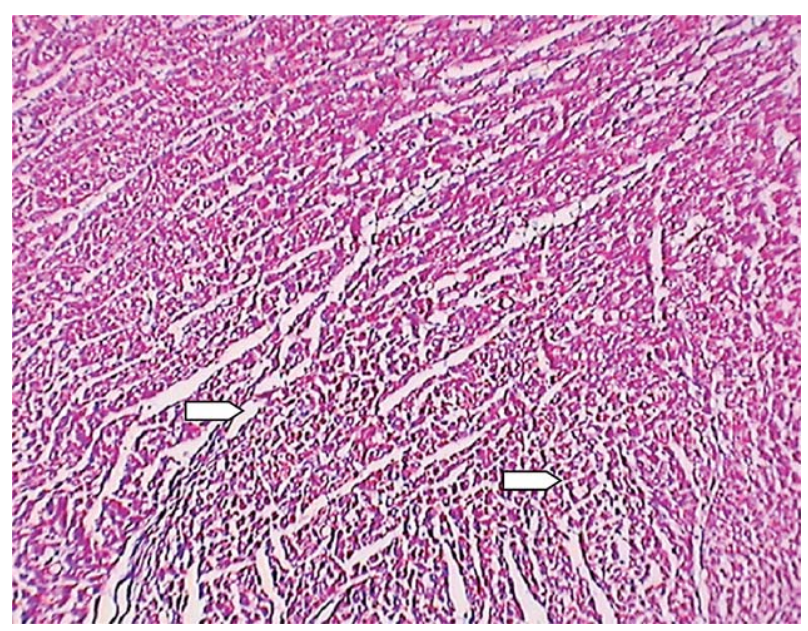

Fig. 8.5. Haematoxylin and eosin staining of heart of rat treated with GIE $(800 \mathrm{mg} / \mathrm{kg}$, po $)$ and ISO $(85 \mathrm{mg} / \mathrm{kg}, \mathrm{sc}) 10 \times 10 \mathrm{x}=100 \mathrm{x}$. Pointers indicate amelioration of myocardial degeneration.

mediated lipid peroxidation and consequent changes in membrane permeability are the major causative factors for cardiotoxicity induced by ISO [18]. Oxidative stress increases cAMP levels by exhausting ATP, depresses sarcolemmal $\mathrm{Ca}^{+2}$ transport resulting in intracellular calcium overload, leading to ventricular dysfunction and contractile failure in rat heart $[19,20]$.

The lesions produced by ISO in rat heart are similar to those found in myofibrillar degeneration in Ischemic Heart Disease (IHD) in man [21]. Hence, the study of ISO induced myocardial necrosis and its underlying mechanisms might provide scientific leads for a better understanding of the pathogenesis of IHD.

Electrocardiograph (ECG) abnormalities are the main criteria generally used for definitive diagnosis of myocardial infarction. The present study shows significant alterations in ECG patterns of isoproterenol injected rats which are in line with earlier reports [22]. These alterations could be due to the loss of cell membrane integrity of the injured myocardial cells.

The $\mathrm{P}$ wave is a small upward deflection on the ECG. It represents atrial depolarization which spreads from the SA node through contractile fibres in both atria. A larger than normal $\mathrm{P}$ wave indicates enlargement of the atrium 
and an enlarged QRS complex which represents ventricular depolarization may indicate a myocardial infarction. Rats treated with ISO alone showed significant reduction in P and QRS wave widths with an increase in P and QRS heights indicating myocardial necrosis. GIE administration to ISO treated rats brought about a significant increase in $\mathrm{P}$ wave and QRS widths and a significant attenuation of the P and QRS wave heights when compared with the ISO control rats, thus exhibiting a cardioprotective action.

PR interval represents the conduction time from the beginning of atrial excitation to the beginning of ventricular excitation, whereas QT interval is the time from the beginning of ventricular depolarization to the end of ventricular repolarization. Both the intervals may be lengthened in case of myocardial damage, ischemia or conduction abnormalities. ISO treated rats exhibited significant prolongation of PR and QT intervals and an increase in heart rate. Rats treated with GIE $400 \mathrm{mg} / \mathrm{kg}$ and GIE $800 \mathrm{mg} / \mathrm{kg}$ showed a significant reduction in the ISO elevated heart rate and prevented significantly the prolongation of the PR and QT intervals brought about by ISO.

The ST segment which begins at the end of the QRS complex and ends at the beginning of the T wave represents the time when the ventricular contractile fibres are depolarized during the plateau phase of the action potential. Isoproterenol injected rats showed a prominent ST segment elevation which is an indication of myocardial infarction, whereas GIE treatment $(400 \mathrm{mg} / \mathrm{kg}$ and $800 \mathrm{mg} / \mathrm{kg}$ ) prevented any significant elevation in ST segment. It can, thus, be noted that the abnormalities in ECG brought about by ISO administration suggesting myocardial necrosis, were alleviated by GIE.

The diagnostic marker enzymes AST, LDH \& CK-MB serve as sensitive probes to assess the degree of myocardial necrosis. Free radicals generated by ISO are known to initiate LPO of membrane bound PUFA, leading to damage of the structural and functional integrity of the myocardium. The myocardium once metabolically impaired, releases its lysosomal marker enzymes into the blood. Hence, the activities of AST, LDH and CK-MB were found to be decreased in the heart homogenates of ISO treated animals and significantly elevated in their sera when compared with normal animals [23].

Attenuation of the ISO raised AST, LDH and CK-MB activities in serum and their elevation in heart by GIE treatment indicates a cardioprotective effect of GIE.

The increased levels of MDA in animals treated with ISO reflect excessive formation of free radicals by autooxidation of ISO, and greater formation of lipid peroxides, resulting in severe damage to the myocardium of these animals. GIE oral treatment significantly reduced the MDA levels by preventing formation of lipid peroxides from PUFA of the myocardium.

Reduced glutathione is one of the most abundant non-enzymatic antioxidant biomolecules present in the body [24]. Together with GPx, GR, CAT and SOD, it efficiently scavenges free radical species such as $\mathrm{H}_{2} \mathrm{O}_{2}$, superoxide anions and alkoxy radicals. It functions as a substrate for antioxidant enzymes GPx and GST to protect cellular constituents from damage due to ROS and peroxides formed during metabolism. Decreased GSH levels in ISO intoxicated rats may be due to its enhanced utilization for augmenting the activities of GPx and GR.

Glutathione levels depleted by ISO were significantly elevated by GIE oral administration. It may be understood that the increased levels of GSH could be due to its enhanced synthesis or improved GR activity in presence of GIE.

SOD, CAT and GPx constitute a mutually supportive enzyme system of the first line cellular defence against oxidative injury, decomposing $\mathrm{O}_{2}$ and $\mathrm{H}_{2} \mathrm{O}_{2}$ before their interaction to form the more harmful hydroxyl (OH.) radical [25].

In the present study, SOD activity decreased significantly in the ISO treated group of animals, which may be due to an excessive formation of superoxide anions. The activities of the $\mathrm{H}_{2} \mathrm{O}_{2}$ scavenging enzymes CAT and GPx also decreased significantly on ISO treatment. The excessive superoxide anions formed lead to inactivation of SOD. In the absence of adequate SOD activity, superoxide anions are not dismuted into $\mathrm{H}_{2} \mathrm{O}_{2}$ which is the substrate for CAT and GPx. This probably results in an inactivation of these $\mathrm{H}_{2} \mathrm{O}_{2}$ scavenging enzymes.

Administration of GIE to ISO challenged rats effectively prevented the depletion of SOD, CAT and GPx activities, which can be correlated to the scavenging of free radicals by GIE, resulting in prevention of depletion of these enzymes [26].

GR is an antioxidant enzyme involved in reduction of GSSG (an end product of GPx reaction) to GSH. In ISO treated rats there was a marked reduction in GPx activity, leading to reduced availability of substrate for GR, resulting in decreased activity of GR. Pre-treatment of GIE to ISO myocardial infarcted rats restored the activity of GR, thus accelerating the conversion of GSSG to GSH. 
The histoarchitecture of cardiac tissue of rats pre-treated with GIE at $400 \mathrm{mg} / \mathrm{kg}$ and $800 \mathrm{mg} / \mathrm{kg}$ showed a dose dependent decrease in infarction and edema with lesser infiltration of inflammatory cells. This might be due to a membrane stabilizing effect of GIE and reduction in inflammation produced by ISO. These results provide additional and substantial evidence of the cardioprotective nature of GIE.

Our earlier studies have shown that ISO $(85 \mathrm{mg} / \mathrm{kg})$ induced moderate lesions in the myocardium and significantly altered various biochemical parameters [25]. Therefore, in the present study the cardioprotective activity of GIE was evaluated against this dose.

The present biochemical and histological studies demonstrated that GIE $800 \mathrm{mg} / \mathrm{kg}$ treatment for 30 days to ISO treated rats was more effective than GIE $400 \mathrm{mg} / \mathrm{kg}$ treatment for 30 days. Based on our present findings it is likely that GIE exerts its cardioprotective effect by stabilizing the myocardial membrane. The membrane stabilizing activity of GIE may be due to an augmentation of basal endogenous antioxidants, which may increase the myocardial antioxidant reserve and strengthen the defense mechanism(s) operating in the myocardium.

This study, thus, aims to bring about value addition to the health benefits of kokoberry, establish it as a "functional food" and promote its use as a culinary spice to enrich people's diets. Besides, it is cheap, readily available to all strata of society, with medicinal properties attributed to it.

\section{Acknowledgments}

We acknowledge the All India Council for Technical Education (AICTE) (New Delhi, India) for providing grantin-aid under its research promotion scheme for this study. We are extremely grateful to Glenmark Pharmaceuticals Ltd., India for providing animals for this study. Thanks are also due to Dr. (Mrs) Chaya Gadgoli of S. V. B. College of Pharmacy, India for her valuable assistance in HPTLC.

\section{References}

[1] Sydney S, Rosamond WD, Howard VJ, Luepker RV. The "Heart Disease and Stroke Statistics-2013 Update" and the Need for a National Cardiovascular Surveillance System, on behalf of the National Forum for Heart Disease and Stroke Prevention. Circulation. 2013;127:21-3.

[2] Whellan DJ. Heart failure disease management: Implementation and outcomes. Cardiol Rev. 2005;13(5):231-9.

[3] Goyal S, Siddiqui MK, Siddiqui KM, Arora S, Mittal R, Joshi S, Singh D. Cardioprotective effect of 'Khamira Abresham Hakim Arshadwala' a Unani formulation in isoproterenol induced myocardial necrosis in rats. Exp Toxicol Pathol. 2010;62:61-74.

[4] Rona G, Chappel CI, Balazs T, Gaudry R. An infarct-like myocardial lesion and other toxic manifestations produced by isoproterenol in the rat. AMA Arch Pathol. 1959;67(4):443-55.

[5] Tilak-Jain JA, Devasagayam TPA. Cardioprotective \& Other Beneficial Effects of Some Indian Medicinal Plants. J Clin Biochem Nutri. 2006;38:9-18.

[6] Shastri BN. The Wealth of India - A Dictionary of Indian Raw Materials and Industrial Products. New Delhi: CSIR. 1956; p. 101-3.

[7] Jena BS, Jayaprakasha GK, Singh RP, Sakariah KK. Chemistry and biochemistry of (-)-hydroxycitric acid from Garcinia. J Agric Food Chem. 2002;50(1):10-22.

[8] Padhye S, Ahmad A, Oswal N, Sarkar FH. Emerging role of Garcinol, the antioxidant chalcone from Garcinia indica Choisy and its synthetic analogs. J Hematol Oncol. 2009;2:38-51.

[9] Lowry OH, Rosebrough NJ, Farr AL, Randall RJ. Protein measurement with the Folin phenol reagent. J Biol Chem. 1951;193(1):265-75.

[10] Ohkawa H, Ohishi N, Yagi K. Assay of lipid peroxides in animal tissues by thiobarbituric acid reaction. Anal Biochem. 1979;95(2):351-8.

[11] Ellman GL. Tissue sulfhydryl groups. Arch Biochem Biophys. 1959;82:70-7.

[12] Sun M, Zigman S. An improved spectrophotometric assay for superoxide dismutase based on epinephrine auto-oxidation. Anal Biochem. 1978;90(1):81-9.

[13] Clairborne A. Catalase Activity. In: Greenwald RA, CRS Handbook of Methods in Oxygen Radical Research. CRS Press, Boca Raton, Florida. 1985;283-4.

[14] Rotruck JT, Pope AL, Ganther HE, Hofeman DG, Hoekstra WG. Selenium: Biochemical role as a component of glutathione peroxidase. Science. 1973;179(4073):588-90.

[15] Mohandas J, Marshal JJ, Duggin GG, Horvath JS, Tiller DG. Low activities of Glutathione-related enzymes as factors in the genesis of urinary bladder cancer. Cancer Res. 1984;44(11):5086-5091. 
[16] Balasubramanyam K, Altaf M, Varier RA, Swaminathan V, Ravindran A, Sadhale PP, Kundu TK. Polyisoprenylated Benzophenone, Garcinol, a Natural Histone Acetyltransferase Inhibitor, Represses Chromatin Transcription and Alters Global Gene Expression. J Biol Chem. 2004;279:33716-26.

[17] Kumar S, Sharma S, Chattopadhyay SK. High-performance liquid chromatography and LC-ESI-MS method for identification and quantification of two isomeric polyisoprenylated benzophenones isoxanthochymol and camboginol in different extracts of Garcinia species. Biomed Chromatogr. 2009;23:888-907.

[18] Noronha-Dutra AA, Steen EM, Woolf N. The correlation between catecholamine and lipid peroxidation induced damage in heart cells. Basic Res Cardiol. 1985;80(Suppl 1):133-6.

[19] Bhagat B, Sullivan JM, Fischer VW, Nadel EM, Dhalla NS. cAMP activity and isoproterenol-induced myocardial injury in rats. Recent Advances in studies on cardiac structure and metabolism. 1976;12:465-70.

[20] Tappia PS, Hata T, Hozaima L, Sandhu MS, Panagia V, Dhalla NS. Role of oxidative stress in catecholamine-induced changes in cardiac sarcolemmal $\mathrm{Ca}^{+2}$ transport. Arch Biochem Biophys. 2001;387(1):85-92.

[21] Milei J, Nunez RG, Rapaport M. Pathogenesis of isoproterenol-induced myocardial lesions: Its relation to human 'coagulative myocytolysis'. Cardiol. 1978;63(3):139-51.

[22] Kralova E, Mokran T, Murin J, Stankovicova T. Electrocardiography in two models of isoproterenol induced left ventricular remodeling. Physiol Res. 2008;57(Suppl 2):S83-9.

[23] Mauro Panteghini. Role and importance of biochemical markers in clinical cardiology. Eur Heart J. 2004;25:1187-96.

[24] Townsend DM, Tew KD, Tapiero H. The importance of glutathione in human disease. Biomed Pharmacother. 2003;57(3-4):145-55.

[25] Panda VS, Naik SR. Cardioprotective activity of Ginkgo biloba Phytosomes in isoproterenol-induced myocardial necrosis in rats: A biochemical and histoarchitectural evaluation. Exp Toxicol Pathol. 2008;60(4,5):397-404.

[26] Tosaki A, Engelman DT, Pali T, Engelman RM, Droy-Lefaix MT. Ginkgo biloba Extract (EGb-761) improves postischemic function in isolated preconditioned working rat hearts. Coronary Artery Dis. 1994;5(5):443-50. 